\title{
HIV and parasitic co-infections among patients seeking care at health facilities in Tanzania
}

\author{
BONIPHACE IDINDILI I,2,* BONIFACE JULLU ${ }^{3}$, JAN HATTENDORF ${ }^{1}$, FERDINAND MUGUSI ${ }^{4}$, \\ GRETCHEN ANTELMAN ${ }^{5}$ and MARCEL TANNER ${ }^{1}$ \\ ${ }^{1}$ Swiss Tropical and Public Health Institute, University of Basel, Socinstrasse 57, 4002 Basel, Switzerland \\ ${ }^{2}$ Tumbi Region Hospital P.O Box 5091 Dar es Salaam, Tanzania \\ ${ }^{3}$ Ifakara Health Institute, P.O Box 53 Ifakara, Tanzania \\ ${ }^{4}$ Muhimbili University of Health and Allied Sciences, P.O. Box 65000, Dar es Salaam, Tanzania \\ International Centre for AIDS Care and Treatment Programs, P O Box 80214, Dar es Salaam, Tanzania
}

\begin{abstract}
Untreated tropical parasitic co-infections appear to speed the progression of HIV-1 disease. However, to date, there have been few studies conducted in resource limited settings to ascertain the interaction of parasitic co-infection where HIV/AIDS management largely depends on CD4+ T lymphocyte cells counts and WHO clinical staging. This study aimed to determine the prevalence of parasites, their association with CD4+ T lymphocyte cells changes and clinical manifestation of HIVinfection in patients attending HIV/AIDS management clinics in Tanzania. Adult HIV-infected patients registering for the first time at HIV/AIDS management clinics were recruited; with physical examination and laboratory tests performed at baseline and after 6 months. Patients were assigned a clinical stage and screened for helminths and Plasmodium sp. co-infection, CD4+ T lymphocyte cells, haemoglobin and HIV-1 p24 antigen. Of the 421 HIV-1 infected patients studied, 198 (47.0\%) were coinfected with one or more parasites. Of those studied, 93/421(22.1\%) had helminth only co-infection, and 50/421(12.9\%) had Plasmodium sp only co-infection. Mixed Plasmodium sp and helminth coinfection was diagnosed in 55/421(13.0\%) patients. Helminths frequently diagnosed included: hookworm 65/421(15.4\%), Schistosomiasis 49/421(11.6\%), Strongyloides stercoralis 57/421(13.5\%), and Ascaris lumbricoides 54/421(12.8\%). No statistical association was found between CD4+ T lymphocyte cells $<200 / \mu \mathrm{l}$, or WHO clinical stage III/IV with parasite co-infections (AOR 1.2, 95\%CI 0.8-1.8). Anaemia was common in parasite co-infected patients (32.8\% vs 18.8\%). Parasite co-infection was associated with risk of anaemia (AOR 2.1, 95\%CI 1.3-3.2). In multivariable logistic regression analysis, baseline CD4+ T lymphocyte cells $<200 / \mu 1$ was significantly associated with CD4+ T lymphocyte cells $<200 / \mu \mathrm{l}$ (AOR 2.4, 95\%CI 1.3-4.7) at six months. HIV-1 P24 antigen mean concentration was higher in parasite co-infected patients (ranges 47.6 to 56.9) as compared to patients without parasite coinfection (5.5). We have looked at one set of parasites and found high prevalence of malaria and helminth co-infection in HIV-infected individuals. Given the available reports on health impacts of helminth co-infection in HIV/AIDS patients and the anecdotal reports of helminth's health effects in HIV-uninfected persons, helminths and other prevalent parasites should not be ignored in HIV/AIDS programs. Based on local helminth epidemiology and HIV-infected cohort specific helminths coinfection prevalence data, mass treatment of soil transmitted helminths can be incorporated into HIV/AIDS management programmes.
\end{abstract}

Key words: parasites, HIV-1, co-infection, patients, Tanzania

\section{Introduction}

HIV-infection and AIDS in sub-Saharan Africa present with diverse clinical characteristics reflecting the variety of prevalent endemic diseases within the region. More than 100 different disease-causing agents are found in the region including viruses, bacteria, fungi,

* Correspondence: Boniphace Idindili: E-Mail: boniphace.idindili@unibas.ch; idindili@yahoo.co.uk 
protozoa, helminths and arthropods (Karp \& Auwaerter., 2007). A relatively small proportion of these pathogens cause the majority of serious health complications experienced by HIV-infected persons (Kaplan et al., 1996). Distribution of these pathogens is geographically sensitive to favourable environments, characterized by social behaviours and ecological factors which affect the risk of transmission (Masur et al., 2000).

Concurrence of HIV and tropical infections affect each other mutually. HIV in patients with parasite infection alters the natural clinical progression of the parasitic diseases, and reduces the efficacy of parasitic treatment (Marques et al., 2007; Kamya et al., 2006). HIV-1 compromises the cellular immune system by destroying CD4+T lymphocyte cells and macrophages; (Reeves \& Piefer, 2005) thus reducing the immune system's ability to resist infection from regionally endemic pathogens (Hughes et al., 2007). HIV-infected persons are susceptible to new infection and reactivation of (Reeves \& Piefer, 2005) latent infections (Karp \& Auwaerter, 2007). As a result, HIV-immunosuppression facilitates infections, increases the severity of infection, changes disease presentation and complicates treatment (Karp \& Neva, 1999). Of particular importance is the increased risk of parasitaemia and clinical malaria in semi-immune HIV-infected adults in malaria endemic regions (French et al., 2001). In addition to HIV-effects on susceptibility and pathogenesis of tropical diseases, people living with tropical infections are at increased risk for HIV-infection and unfavourable disease progression (Bentwich et al., 2000).

Health effects of parasitic co-infections in HIV-infected persons marked HIV/AIDS clinical manifestations in the early decades of the HIV epidemic. For example, protozoa infections caused chronic diarrhoea which resulted in wasting (slim disease), chronic fever without an obvious source, and pulmonary disease syndromes; all symptoms used to classify AIDS in sub Saharan Africa (Grant et al., 1997) (Kaplan et al., 1996). There is evidence that helminth species specifically alter HIV disease progression. Interaction of Schistosome and HIV-infections with host CD4+ T lymphocyte cells leads to bi-directional effects, which are different from sequelae caused by an infectious agent alone (Secor, 2006). Helminth infections leads to greater HIV-replication and disease progression, through immune activation of cellular mechanisms rendering the CD4+T lymphocyte cells susceptible to HIV-infection and resulting in increased viral load (Shapira-Nahor et al., 1998). High viral load is associated with rapid CD4+ T lymphocyte cells death and disease progression to AIDS (Borkow \& Bentwich, 2006). Untreated Strongyloides stercoralis causes hyper-infection syndrome in immunosuppressed patients after initiation of antiretroviral therapy (ART). It is difficult to distinguish between the clinical manifestation of strongyloidiasis hyper-infection syndrome and the immune-reconstitution syndrome induced by HAART in patients with CD4+ T lymphocyte cells $<200 / \mu l$; both conditions are fatal without proper management (Concha et al., 2005; Lewthwaite et al., 2005).

Although scientists still debate on the survival benefit of routine screening and treatment for helminths and other parasitic infection in HIV-infected patients, helminths and malaria infections continue to cause morbidity and aggravated mortality (French et al., 2001). Treatment of parasitic infections could provide an immediate benefit in areas where both HIV-1 and helminths are prevalent.

Tanzania has overlapping, high prevalence rates of HIV and parasitic infections (Beck et al., 2008). Scaling up of HIV and AIDS management services has become wellestablished and widely available, allowing quality of care to become increasingly important 
to investigate and improve. This opens the door for identifying HIV co-infections with latent helminths and malaria as important areas to investigate.

Untreated tropical parasitic co-infections appear to speed the progression of HIV-1 disease. However, to date, there have been few studies conducted in resource limited settings to ascertain the interaction of parasitic co-infection where HIV/AIDS management largely depends on CD4+T lymphocyte cells counts and WHO clinical staging guidelines. This study aimed to determine the prevalence of parasites, their association with CD4+T lymphocyte cells changes and clinical classification of HIV-infection in patients attending management clinics in Tanzania.

\section{Materials and Methods}

\section{Study area}

The study was conducted at Tumbi Regional Hospital (urban) and Chalinze Health Center (peri-urban) in Pwani Region, Eastern Tanzania between April 2008 and March 2009. Tumbi Regional Hospital is located $40 \mathrm{~km}$ from Dar es Salaam, the commercial capital of Tanzania. The hospital has a bed capacity of 200 beds and serves as a regional specialized Hospital. Chalinze Health Center is located $70 \mathrm{~km}$ from Tumbi Hospital at the junction of the main upcountry. Both heath facilities provide services to a mixture of patients from urban and rural villages. Most residents of Chalinze reside in rural villages and generate income from farming and trading of different types of goods.

\section{Study population}

We studied newly enrolled adult HIV-infected patients attending HIV/AIDS management services at Tumbi Hospital and Chalinze Health Center. Patients residing in the catchments areas of both Tumbi Hospital and Chalinze Health Center were selected for inclusion in the study. Exclusion criteria included: less than 18 years of age, pregnancy, and patients with obviously severe disease conditions (i.e. Tuberculosis, Cryptococcus Meningitis, Pneumonia and generalized Kaposi's sarcoma) or necessary transfer to another clinic.

A study nurse identified eligible patients after completing routine clinic registration procedures. Patients were individually screened for eligibility after which a standardized informed consent was administered. Consenting patients were assigned a study identification number which was affixed to the clinic card and case file. The patient was then referred to a study clinician for clinical examination. Study clinicians recorded patients' clinical history, performed physical examinations and staging of HIV according to the Tanzania and WHO clinical guidelines for management of HIV and AIDS. Patients were referred to the laboratory for sample collection.

\section{Specimen collection and processing}

Blood specimens were collected in EDTA tubes for enumeration of CD4+ T lymphocyte cells, haemoglobin and malaria smear, while part of the sample was frozen and shipped to Ifakara Health Institute laboratory for HIV-1 P24 plasma ELISA assays. Fresh stool samples were collected in sterilized plastic containers, preserved in 10\% formalin and examined within 24 hours by formol-ether concentration techniques (Marti \& Escher., 1990). In stool samples found to contain ova or larvae, intensity of infection was estimated by quantitative analysis of the egg burden according to the Kato-Katz thick-smear technique. Patients who could not 
produce stool during the clinic visit were provided with sterile plastic containers and asked to bring a fresh stool specimen on their next visit. Sterile plastic containers were also used to collect a clean-catch urine specimen.

Malaria, urine and haemoglobin results were returned to the patient on the same day, while other test results were available at subsequent visits. Study patients were scheduled a follow-up visit 14 days after initial enrolment to complete ART eligibility, counselling and other assessments. Patients received standard treatment according to infections diagnosed: malaria was treated using Coartem (artemether $20 \mathrm{mg} / \mathrm{lumefantrine}$ $120 \mathrm{mg}$ ), intestinal helminths were treated with Albendazole (400mg day one and 200mg 2 subsequent days), and Schistosomiasis was treated with Praziquantel (40mg/kg divided into 2 doses, 6 hours apart). After the 14th day visit, study patients were scheduled to follow-up with monthly visits, regardless of ART status. The $6^{\text {th }}$ month follow-up visit was scheduled for patients during their subsequent clinic visits. Clinical examination and laboratory procedures performed at initial enrolment were repeated at the $6^{\text {th }}$ month visit.

Specimens for CD4+ T lymphocyte cells, haemoglobin, malaria, sputum, and urine and stool samples were analyzed at Tumbi Hospital laboratory. CD4+ T lymphocyte cells analysis was performed using automated FACS count (BD Biosciences, California, USA). Biochemistry and haematological parameters were analyzed using a Biochemical analyzer (Italy) and haematological analyzer (Pentra 80, France) respectively. Malaria smears were Giemsa stained and microscopically examined for parasitaemia. Sputum specimens were stained using Ziehl-Neelsen technique and examined for mycobacterium tuberculosis.

Stool samples were fixed using sodium acetate-acetic acid-formalin (SAF) solution and microscopically examined for parasites and helminths. A sample of the fresh stool was cultured in Xylose Lysine Deoxycholate Agar (XLD) media for Salmonella and Shigella. Direct microscopic examination was performed on urine samples. HIV-1 P24 sample analysis was conducted with the Ifakara Health Institute's adapted PerkinElmer Life Sciences's "P24 Ultra sensitive Assay Protocol" (ELAST® kit) (Knuchel et al., 2007)].

\section{Data analysis}

Data was entered into Microsoft @Access, and analyzed using Stata Intercooled version 9. Standard definitions of severe immunological suppression were used to describe the magnitude of CD4+T lymphocyte cells decline. Patients with CD4+ T lymphocyte cells counts below and above 200 cells/ $\mu$ l were categorized as severely and moderately immunosuppressed, respectively. Logistic regression models were used to generate odds ratios associated with CD4+ T lymphocyte cells $<200 / \mu 1$. An attempt was made to compare patient groups according to the specific helminth infection, but was limited by small samples of each patient helminths infected group.

\section{Ethical considerations}

The study received scientific and ethical approval from the Muhimbili University of Health and Allied Sciences Research Ethics Review Board (Ref.No.MU/RP/AEC/Vol.XII/58). Permission was granted by the appropriate Region, District and hospital authorities. Informed consent for participation was obtained from patients using Kiswahili, the local language. 


\section{Results}

\section{Baseline characteristics}

A total of 464 subjects were enrolled into the study between April 2008 and March 2009, with 421 patients completing baseline data for analysis. Forty three patients were excluded from the analysis because of insufficient samples for parasitological diagnosis. Patients excluded did not differ from the remaining patients in terms of socio-demographic characteristics, CD4 cell counts and clinical presentation at the time of enrolment.

The mean age of participants was 35.7(SD 34.6 to 36.9) years and the mean body weight was $51.6 \mathrm{~kg}$ (SD 50.0 to 53.1). The majority of patients were women $261 / 421(62 \%)$. In total $272 / 421(64.6 \%)$ of patients were living in rural areas with a high proportion of all patients having completed primary education 336/421 (80\%). There were no remarkable differences between patient groups. The majority of patients used pit latrines for excreta disposal and obtained water for domestic use from mixed sources (

Table 1: Baseline demographic, social and clinical characteristics of patients by parasites status attended at Tumbi Hospital and Chalinze Health Centre, April 2008- March 2009

\begin{tabular}{|c|c|c|c|c|c|}
\hline Characteristics & Response & $\begin{array}{l}\text { Patients } \\
\text { without } \\
\text { parasites } \\
\mathrm{N}=223\end{array}$ & $\begin{array}{l}\text { Patients } \\
\text { with } \\
\text { helminths } \\
\text { only } N=93\end{array}$ & $\begin{array}{l}\text { Patients } \\
\text { with } \\
\text { malaria } \\
\text { only } N=50\end{array}$ & $\begin{array}{l}\text { Mixed } \\
\text { helminths } \\
\text { and malaria } \\
\mathrm{N}=55\end{array}$ \\
\hline \multicolumn{2}{|l|}{ Weight-kg mean(SD) } & $51.4(1.3)$ & $49.2(1.2)$ & $52.5(1.2)$ & $48.7(1.2)$ \\
\hline \multicolumn{2}{|l|}{$\begin{array}{l}\text { Age in years, } \\
\text { mean(SD) }\end{array}$} & $35.7(1.3)$ & $36.0(1.3)$ & $35.5(1.3)$ & $34.7(1.3)$ \\
\hline \multirow[t]{2}{*}{$\operatorname{Sex} \mathrm{n}(\%)$} & Women & $147(65.9)$ & $51(54.8)$ & $30(60.0)$ & $33(60.0)$ \\
\hline & Men & $76(34.1)$ & $42(45.2)$ & $20(40.0)$ & $22(40.0)$ \\
\hline \multirow[t]{2}{*}{$\begin{array}{l}\text { Residential status } n \\
(\%)\end{array}$} & Rural & $146(65.5)$ & $57(61.3)$ & $28(56.0)$ & $41(74.6)$ \\
\hline & Urban & $77(34.5)$ & $36(38.7)$ & $22(44.0)$ & $14(25.4)$ \\
\hline \multirow[t]{3}{*}{ Education n (\%) } & $\begin{array}{l}\text { Incomplete } \\
\text { primary }\end{array}$ & $28(12.6)$ & $8(8.7)$ & $7(14.0)$ & $6(10.9)$ \\
\hline & Primary & $173(77.6)$ & $78(84.8)$ & $41(82.0)$ & $44(80.0)$ \\
\hline & College & $22(9.8)$ & $6(6.5)$ & $2(4.0)$ & $5(9.1)$ \\
\hline \multirow{4}{*}{$\begin{array}{l}\text { Marital status n (\%) } \\
\text { Married/cohabiting } \\
\text { Single } \\
\text { Widowed } \\
\text { Separated/Divorced }\end{array}$} & Married/cohabiting & $104(46.6)$ & $35(38.0)$ & $24(48.0)$ & $21(38.2)$ \\
\hline & Single & $66(29.6)$ & $35(38.0)$ & $12(24.0)$ & $21(38.2)$ \\
\hline & Widowed & $47(21.1)$ & $16(17.4)$ & $10(20.0)$ & $6(10.9)$ \\
\hline & Separated/Divorced & $6(2.7)$ & $6(6.6)$ & $4(8.0)$ & $7(12.7)$ \\
\hline \multirow{3}{*}{$\begin{array}{l}\text { Source of } \\
\text { supply } \mathrm{n}(\%)\end{array}$} & Home tap & $13(5.8)$ & $4(4.3)$ & $6(12.0)$ & $5(9.1)$ \\
\hline & Well or river & $43(19.3)$ & $19(20.7)$ & $9(18.0)$ & $13(23.6)$ \\
\hline & Mixed & $167(74.9)$ & $69(75.0)$ & $35(70)$ & $37(67.3)$ \\
\hline \multirow[t]{3}{*}{ Types of latrine $\mathrm{n}(\%)$} & Pit & $170(76.2)$ & $73(78.5)$ & $42(84.0)$ & $42(76.4)$ \\
\hline & Flush & $22(9.9)$ & 11(11.9) & $7(14.0)$ & $10(18.2)$ \\
\hline & No latrine & $31(13.9)$ & $8(8.7)$ & $1(2.0)$ & $3(5.4)$ \\
\hline
\end{tabular}


Among the $421 \mathrm{HIV}-1$ infected patients included in data analysis at initial assessment, $198(47 \%)$ were found to be co-infected with one or more parasites. Helminth only co-infection was diagnosed in 93/421 (22.1\%) patients, while 50/421 (11.9\%) patients exhibited Plasmodium sp. parasitaemia but no helminth coinfection. Mixed Plasmodium sp and helminth co-infection was diagnosed in 55/421 $(13.1 \%)$ patients ( ) .

Plasmodium sp. was the most common parasite isolated 105/421(24.9\%). Of the helminths diagnosed, most frequently detected were: hookworm 65/421(15.4\%), Schistosome 49/421(11.6\%), Strongyloides stercoralis 57/421(13.5\%), and Ascaris lumbricoides 54/421(12.8\%). Parasite infected patients had one and sometimes up to five types of parasites. Multiple parasites were diagnosed in 89/421(21.1\%) patients. Only one patient was found to harbour all five parasites (Table 5).

Table 1: Number of parasites infections, WHO stage and mean HIV-P24 of HIV/AIDS patients grouped according to CD4+ T lymphocyte cells categories

\begin{tabular}{|c|c|c|c|c|c|c|c|}
\hline $\begin{array}{l}\text { CD4+ } T \\
\text { lymphocyte }\end{array}$ & $\begin{array}{l}\text { Number } \\
\text { individual }\end{array}$ & ${ }^{*}$ & site & ies per & WHO Stage & & HIV-1 P24 \\
\hline cells category & 0 & 1 & 2 & $\geq 3$ & I/II & III/IV & Mean (SD) \\
\hline $\begin{array}{l}\text { CD4>200/ul } \\
N(\%)\end{array}$ & $97(43.5)$ & $48(44.0)$ & $17(28.8)$ & 11(36.7) & $100(54.4)$ & $73(30.8)$ & $5.4(20.9)$ \\
\hline $\begin{array}{l}\text { CD4<200/ul } \\
N(\%)\end{array}$ & $126(56.5)$ & $61(56.0)$ & $42(71.2)$ & $19(63.3)$ & $84(45.6)$ & $164(69.2)$ & $30.4(16.2)$ \\
\hline Total & $223(100)$ & 109(100) & $59(100)$ & $30(100)$ & 184(100) & $237(100)$ & $15.3(20.3)$ \\
\hline
\end{tabular}

*Test for trend across ordered groups: $\mathrm{Z}=1.69, P=0.09$

At the time of enrolment into the study, more than half of the HIV+ patients were in clinical stages III/IV and had CD4+Tcells <200/ $\mu$ l (237/421(56.3\%) and 248/421(58.9\%) respectively. The mean HIV-1 p24 concentration was 15.3 (SD 20.3). A higher HIV-1 p24 concentration was found in patients with lower CD4+ T lymphocyte cells counts and WHO clinical stages III/IV. An additional finding was the high concentration of HIV-P24 antigens in patients with parasite co-infection (Helminths 47.6pg/ml, Malaria $49.7 \mathrm{pg} / \mathrm{ml}$ and mixed helminths /malaria $56.9 \mathrm{pg} / \mathrm{ml}$ ) compared to patients without parasites $(5.5 \mathrm{pg} / \mathrm{ml})$. High concentration of HIV-1 P24 is associated with rapid HIV-1 disease progression.

\section{Effect of parasite co-infection on CD4+Tcells, anaemia and WHO clinical stages}

Overall, parasite infected patients had lower CD4+ T lymphocyte cells counts than parasite free patients, but this was not statistically significant (Table 6). Multiple infection was associated with CD4+Tcells <200/ $\mu$ l (1 vs. 2 parasites: OR 1.9, 95\%CI 1.2-3.5; 1 vs. $3-5$ parasites: OR $2.3,95 \%$ CI 1.5-10.7) than one parasite co-infection. The test for trend across ordered groups provided some evidence that the number of 
parasites is associated with low CD4+T lymphocyte cells counts. However, the result was only marginally significant $(Z=1.69, P=0.09)$ (Table 5).

The associations of CD4+T lymphocyte cells $<200 / \mu 1$, anaemia (haemoglobin $<8.0 \mathrm{~g} / \mathrm{dl}$ ) and WHO clinical stage III/IV were examined in patients with and without parasite co-infections (Table 6). No statistically significant differences were observed between patients with and without parasite co-infection in association with CD4+T lymphocyte cells <200/ $\mu$ l. The adjusted odds ratios for parasite co-infected patients was less than one, except for patients with mixed malaria and helminths, any helminths, strongyloides and Ascaris lumbricoides only infections ( $\mathrm{OR}=1.2,1.6,1.5$ and 2.2 respectively).

Table 2: Univariate analysis of the association between parasites and clinical parameters before initiation of ART and other treatment of HIV and AIDS patients

\begin{tabular}{|c|c|c|c|c|c|c|}
\hline \multirow[b]{2}{*}{$\begin{array}{l}\text { Infection } \\
\text { status }\end{array}$} & \multicolumn{2}{|c|}{$\begin{array}{l}\text { CD4+ T lymphocyte cells } \\
\text { count } / \mu 1\end{array}$} & \multicolumn{2}{|c|}{ Haemoglobin g/dl } & \multicolumn{2}{|c|}{ WHO clinical stage } \\
\hline & CD4<200 (\%) & $\begin{array}{l}\mathrm{AOR}^{*} \\
(95 \% \mathrm{CI})\end{array}$ & $\mathrm{HB}<8.0(\%)$ & $\begin{array}{l}\mathrm{AOR}^{*} \\
(95 \% \mathrm{CI})\end{array}$ & III/IV (\%) & $\begin{array}{l}\mathrm{AOR}^{*} \\
(95 \% \mathrm{CI})\end{array}$ \\
\hline No infection & $126 / 223(56.5)$ & Reference & $42 / 223(18.8)$ & Reference & $121 / 223(54.3)$ & Reference \\
\hline Any parasites & $122 / 198(61.1)$ & $1.2(0.8-1.8)$ & 64/198(32.5) & 2.1(1.3-3.2) & $116 / 198(58.6)$ & $1.2(0.8-1.8)$ \\
\hline Malaria only & $27 / 50(54.0)$ & $0.9(0.5-1.7)$ & $12 / 50(24.0)$ & $1.4(0.7-3.0)$ & $25 / 50(50.0)$ & $0.8(0.4-1.5)$ \\
\hline $\begin{array}{l}\text { Helminths+ } \\
\text { Malaria }\end{array}$ & $33 / 55(60.0)$ & $1.2(0.6-2.1)$ & $25 / 55(45.5)$ & $3.8(1.9-7.1)$ & $32 / 55(58.2)$ & $1.2(0.7-2.2)$ \\
\hline $\begin{array}{l}\text { Helminths } \\
\text { only }\end{array}$ & 62/93(66.7) & $1.6(0.9-2.6)$ & 28/93(30.1) & $1.9(1.1-3.3)$ & $59 / 93(63.4)$ & $1.5(0.9-2.5)$ \\
\hline Hookworm & 7/15(46.7) & $0.6(0.6-1.8)$ & $5 / 15(33.3)$ & $2.1(0.9-6.7)$ & $10 / 15(66.7)$ & $1.6(0.5-4.8)$ \\
\hline Schistosome & $6 / 13(46.2)$ & $0.7(0.2-2.2)$ & $2 / 13(15.4)$ & $0.9(0.2-4.5)$ & $5 / 13(38.5)$ & $0.6(0.2-1.8)$ \\
\hline S. stercoralis & $9 / 14(75.0)$ & $1.5(0.5-4.5)$ & $1 / 14(7.1)$ & $0.4(0.1-2.9)$ & $9 / 14(64.3)$ & $1.5(0.5-4.7)$ \\
\hline A.lumbricoides & 11/15(73.3) & $2.2(0.8-7.2)$ & $8 / 15(53.3)$ & $5.3(1.8-15.7)$ & $10 / 15(66.7)$ & $1.7(0.6-5.2)$ \\
\hline
\end{tabular}

${ }^{*}$ Odds ratios adjusted to age and sex

The prevalence of anaemia was higher $64 / 198(32.5 \%)$ in parasite co-infected when compared to patients without co-infection42/223(18.8\%). Parasite co-infection was associated with significant risk of anaemia (AOR 2.1,95\%CI 1.3 to 3.2). The odds of having anaemia were high in patients with mixed helminths and malaria infection, increased by a factor more than 3 (AOR=3.8, 95\% CI 1.9 to 7.1) when compared to patients without co-infection. There was a strong association between Ascaris lumbricoides and anaemia (AOR=5.3, 95\%CI 1.8 to 15.7). Patients with any helminth infection had almost two times the odds of having anaemia (AOR 1.9, 95\%CI (1.1-3.3). Similarly, patients co-infected with hookworm had two times the odds (AOR=2.1, 95\% CI 0.9-6.7) of having severe anaemia. However, this association was not statistically significant. The associations between either Strongyloides stercoralis or Schistosomiasis and anaemia were affected by small sample sizes, and did not demonstrate any statistically significant association with anaemia (AOR 0.4, 95\%CI 0.1-2.9, AOR 0.9, 95\%CI 0.2-4.5 respectively). However, it is known that Schistosoma haematobium causes 
moderate anaemia. Neither multiple co-infection with any parasites (AOR 1.2, 95\%CI 0.8-1.8) nor with single infection (AOR 0.8-1.7, 95\% CI 0.4-5.2) was significantly associated with WHO clinical stages III/IV.

\section{Changes in CD4+ T lymphocyte cells counts after treatment}

Of the 421 patients included in baseline analysis, one patient died and 18 patients were infected or re-infected with parasites during the 6 months follow-up period. At the completion of the 6 month follow-up, 196 (98.9\%) of patients with parasites and 222 (99.6\%) of patients without parasites at enrolment had complete data for analysis. In total 312(74.1\%) patients were started on ART during the period. We observed an increase in CD4+ T lymphocyte cells counts at six months in the majority of ART patients both with and without parasites. Patients with parasites at baseline 151/196(77.0\%) experienced an increase in CD4+ T lymphocyte cells counts; the majority being those taking ART treatment 129/151(85.4\%). Similarly, for patients without parasite co-infection, 147/222(66.2\%) CD4+ T lymphocyte cells counts increased $125 / 147(85.0 \%)$ with the majority being patients on ART treatment. The mean CD4+ T lymphocyte cells count increase found was 111.6(9.0) and 108.6(8.2) in patients with and without parasite infection at baseline, respectively.

Table 3: Changes in CD4+ T lymphocyte cells counts between baseline and after six months of HIV/AIDS patients

\begin{tabular}{|c|c|c|c|c|c|c|c|c|c|}
\hline \multirow[t]{3}{*}{ ART status } & \multicolumn{4}{|c|}{ With parasites at Baseline $\mathrm{N}=196$} & \multicolumn{4}{|c|}{ No parasites at Baseline $\mathrm{N}=\mathbf{2 2 2}$} & \multirow{3}{*}{$\begin{array}{l}\text { New } \\
\text { /re- } \\
\text { infection }\end{array}$} \\
\hline & \multicolumn{2}{|c|}{ Mean CD4 increase } & \multicolumn{2}{|c|}{ Mean CD4 decrease } & \multicolumn{2}{|c|}{ Mean CD4 increase } & \multicolumn{2}{|c|}{ Mean CD4 decrease } & \\
\hline & N (\%) & $\begin{array}{l}\text { Mean } \\
\text { (SD) }\end{array}$ & N (\%) & $\begin{array}{l}\text { Mean } \\
\text { (SD) }\end{array}$ & N (\%) & $\begin{array}{l}\text { Mean } \\
\text { (SD) }\end{array}$ & $\mathbf{N}(\%)$ & $\begin{array}{l}\text { Mean } \\
\text { (SD) }\end{array}$ & \\
\hline ART & $129(85.4)$ & $129.9(1.9)$ & $19(42.2)$ & $54.7(2.3)$ & $125(85.0)$ & $118.4(1.9)$ & $23(30.7)$ & $47.5(2.9)$ & $16(88.9)$ \\
\hline $\begin{array}{l}\text { Not } \\
\text { ART }\end{array}$ & 22(14.6) & $60.2(2.8)$ & $26(57.8)$ & $181.4(2.1)$ & $22(14.9)$ & $66.7(2.5)$ & $52(69.3)$ & $157.8(2.9)$ & $2(11.1)$ \\
\hline Total & 151(100) & $111.6(2.2)$ & $45(100)$ & $109.3(2.7)$ & 147(100) & $108.6(2.1)$ & $75(100)$ & 109.2(3.4) & $18(100)$ \\
\hline
\end{tabular}

The CD4+ T lymphocyte cells counts decreased between enrolment and 6 month follow-up in 45/196 (22.9\%) patients with parasites and 75/222(33.7\%) patients without parasites. The mean CD4+ T lymphocyte cells count decrease was 109.3(SD 14.9) and 101.2(SD 29.9) in patients with and without parasites, respectively. A statistically significant difference was observed between patients with parasite co-infection who experienced CD4+ T lymphocyte cells count increase and those whose CD4+ T lymphocyte cells count decreased $(p=0.001)$. Similar results were observed in patients without parasites.

Table 4: Multivariable Logistic Regression for predictors of CD4+ T lymphocyte cells $<200 / \mu 1$ after 6 months of follow-up of HIV and AIDS patients attended

\begin{tabular}{ll}
\hline Variables & Adjusted OR(95\%CI) \\
\hline Female & $0.9(0.6-1.4)$ \\
Baseline CD4+ T lymphocyte cells counts* & $2.4(1.3-4.7)$ \\
Baseline P24 Antigen levels & $1.0(0.9-1.1)$ \\
Baseline WHO clinical stage** & $1.0(0.7-1.6)$ \\
ART treatment & $1.3(0.6-2.6)$ \\
Helminths or malaria new/re-infection & $1.6(0.4-5.7)$ \\
\hline
\end{tabular}


*Reference category CD4+ T lymphocyte cells $>200 / \mu l . ~ * *$ Reference category WHO clinical stage I/II

Variables known to be associated with CD4+ T lymphocyte cells count changes were included in multivariable logistic regression analysis. Baseline CD4+ T lymphocyte cells $<200 / \mu \mathrm{l}$ were significantly (AOR 2.4, 95\%CI 1.3-4.7) associated with CD4+ T lymphocyte cells $<200 / \mu \mathrm{l}$ at six months (Table 8 ). New infections with helminths or malaria were not associated with CD4+ T lymphocyte cells $<200 / \mu 1$ at six months (AOR 1.6, 95\% CI 0.4-5.7). This is probably due to low parasite infection intensity to impact CD4+ T lymphocyte cells changes within the follow up period. The impact of P24 and WHO clinical stages in predicting CD4+ T lymphocyte cells $<200 / \mu 1$ at six months was directly influenced by the initiation of ART (AOR 1.0, 95\% CI 0.7 to 1.6).

\section{Discussion}

This study found malaria and helminth co-infection more frequent in HIV-infected patients than any other parasite. The prevalence of helminths was $22.1 \%$ lower than study findings in other sub-Saharan African settings (S. Assefa et al., 2009) (Modjarrad et al., 2005) but higher than results from other studies in rural Tanzania (Tarimo et al., 1996)] (Nielsen et al., 2007)]. We isolated hookworm, A. lumbricoides, and Strongyloides stercoralis in patients with CD4+ T lymphocyte cells $<200 \mu / 1$ rather than the common HIV-related protozoa; which marked early AIDS manifestation as causes of chronic diarrhoea. These findings may be setting specific, or a phenomenon of changing AIDS manifestation, because previous studies have reported higher prevalence rates of Cryptosporidium and Isospora belli among HIVinfected patients (Assefa et al., 2009; Kelly et al., 2009).

The prevalence of malaria co-infection in our study population was $24.9 \%$ higher than findings in previous studies of Eastern Africa (James Whitworth et al., 2000), (French et al., 2001). The high malaria parasitaemia in this, and other studies, points to an important interaction between HIV-1 and malaria; especially in our setting where a large population of severely immunodeficiency patients and endemic malaria coexist. Malaria is known to cause an increase in transitory viral load while HIV-1 causes more clinical malaria, higher parasitaemia and higher rates of treatment failure in co-infected patients (Kamya et al., 2006; Martin-Blondel et al., 2009).

Mixed parasite infection is common in areas where various types of parasites coexist with favourable behavioural and ecological patterns of transmission. The occurrence of polyparasitism in the current study showed an inverse relationship with CD4+ T lymphocyte cells $<200 \mu / 1$. Health effects of polyparasitism depend on the types of parasite co-infection, mixed intestinal helminths and protozoa cause persistent diarrhoea and anaemia. In the case of mixed helminth and malaria infection, malaria can worsen mild anaemia due to helminths and exacerbate the HIV-infection outcome. Although this study did show a marginal statistically significant trend towards severe immunodeficiency as a result of polyparasitism; it highlights an 
important interaction in settings with higher prevalence of HIV-1 and parasite infection. Therefore, parasite co-infection in HIV and AIDS patients should not be ignored. Site specific assessments need to be carried out to determine the relevance and abundance of parasites to that particular region, so as to inform the basis for an intervention approach.

It is well established that CD4+ T lymphocyte cells $<200 \mu / 1$ is associated with a higher risk of opportunistic infection and poor disease progression (Goujard et al., 2006). Parasite co-infection, conversely, facilitates CD4+ T lymphocyte cells decline (Secor, 2006) through various mechanisms. This study demonstrated a statistically significant association between multiple parasite co-infections and CD4+ T lymphocyte cells $<200 \mu / 1$ before treatment, with the odds ratios showing some association. Therefore, parasite co-infection increases the risk of opportunistic infection in HIV-infected patients. Then, these study findings give the indication of a possible association in settings with high infection intensities and their impact on CD4+ T lymphocyte cells decline.

The association of helminths and CD4+ T lymphocyte cells $<200 \mu / 1$ in this study was also affected by the low intensities of helminth infection and re-infection that occurred after treatment. An attempt was made to analyze each individual helminth species effects, but the samples were insufficient to provide a basis for inference. Parasite re-infection, and failure to control for the duration of infection, complicated the estimation of the true effects of helminths on CD4+ T lymphocyte cells decline. It is difficult to determine the duration of infection until the occurrence of CD4+ T lymphocyte cells decline. Cohort studies in different settings of high and low parasite prevalence intensities can provide adequate information on the specific interaction of helminths and HIV-infection. Health seeking behaviour is one important factor to consider as a cofounder in the role of helminths co-infection on CD4+ $\mathrm{T}$ lymphocyte cells decline. Late presentation is a common phenomenon in this setting, with a majority of patients seeking health care after having advanced immunodeficiency. Thus, making it difficult to establish which was the cause and effect between helminths infection and CD4+ T lymphocyte cells decline.

Our study population consisted of patients exposed to common, known risk factors for helminth infection transmission; mostly persons with only primary level education, limited access to a safe water supply; and using pit latrine, though some do not use any latrine. Therefore, human faeces pollution and high rates of helminths transmitted through soil is evident in this population. Improved sanitation, combined with de-worming programs, is most likely to eliminate helminth transmission. Although the current de-worming programs are focused on school children who carry the highest burden of helminth infection, the prevalence of helminths in adults is also substantial because of transmission to the adult population (Eziefula \& Brown., 2008). Routine, mass treatment in HIV-infected persons can be beneficial and provides an appropriate alternative public health 
approach to routine screening and treatment; especially in regions with a high burden of helminths.

Anaemia is a common complication occurring in $20-80 \%$ of HIV-infected patients and is also associated with rapid disease progression and mortality (Harris et al., 2008). The prevalence of anaemia in our study was significantly associated with any of the parasite co-infections. The impact of parasite co-infection on anaemia was more significant in patients with malaria and helminth polyparasitism. Such an association was not demonstrated in patients without parasite co-infection. HIVinfection can lead to anaemia in many ways in HIV-infected patients (Paton et al., 2006). Our results show the additive effects of parasite co-infection on other causes of anaemia in HIV-infected patients. In areas where HIV-infection, helminths and anaemia are prevalent; the interaction of anaemia and helminths or malaria in HIVinfection need to be emphasized despite inadequate diagnosis facilities. In such settings some patients, even when HIV-replication is controlled by ART, may continue to experience poor health due to anaemia secondary to parasites infection. Increased CD4+Tcells susceptibility to HIV-infection caused by helminths coinfection was demonstrated by finding of a strong association between helminth coinfection and higher HIV-1 P24 antigen concentrations. This positive association can be explained by the in vivo activation of CD4+ $\mathrm{T}$ lymphocyte cells increased susceptibility to HIV-infection and rapidly HIV-replication in helminth co-infected HIV-patients compared to uninfected patients. HIV-1 P24 antigen level $>5 \mathrm{pg} / \mathrm{ml}$ predicts disease progression comparable to CD4+ T lymphocyte cells $<350 / \mu 1$ (Schüpbach, 2003).

We found higher HIV-1 P24 antigen concentration in parasite co-infected patients with the majority of them needing ART for survival. These findings are contrary to previous reports that show higher viral loads in helminth-free participants (Wolday et al., 2002).

A noticeable increase in $\mathrm{CD} 4+\mathrm{T}$ lymphocyte cells was recorded in both parasites coinfected and uninfected patients between enrolment and at 6 months. This change cannot be exclusively associated with treatment of helminth and malaria parasites. Our patients were given Cotrimoxazole and ARVs together with treatment for parasites. A statistically significant difference in CD4+ T lymphocyte cells increase was observed between the parasites co-infected and uninfected patients. This was because a higher proportion of parasite co-infected patients had CD4+ T lymphocyte cells $<200 \mu / 1$ and started earlier ART compared to uninfected patients. Therefore, helminth or parasite co-infection treatment benefits are more increased if combined with ART and Cotrimoxazole. Cohort studies comparing very high and very low parasite intensities in HIV-1 co-infected patients can provide useful information on the minimum essential burden of parasites responsible for CD4+ T lymphocyte cells changes.

We have looked at one set of parasites and found high prevalence of malaria and helminth co-infection. Given the available various reports on parasite co-infection in 
HIV and AIDS patients, parasites should not be ignored in HIV and AIDS programmes. Incorporation of these programs should not wait until the conclusion of the ongoing debate to de-worm or not de-worm. Instead, parasite co-infection in HIV-infected patients' area specific prevalence data can be used confidently to guide management programs. In low parasite prevalence settings routine diagnostic screening is recommended and in settings with high parasite prevalence, mass treatment should be considered.

\section{Competing interest}

No competing interests expressed by authors.

Acknowledgements

The authors express their sincere gratitude to the patients who participated in this research. We thank all of the health workers at HIV/AIDS Management clinics and the laboratory staff of Tumbi Hospital and Chalinze health Centre. We acknowledge the following for their valuable contributions: Rhoda Msemo (Bagamoyo District Executive Director), Dr. Koheleth Winani (Medical in-charge Tumbi Hospital), Dr. Marcel Stöckle, Susan Rumisha, Margrit Sloui, Sophia Ndwaki, Mwajuma Makala, Rose Mosses, Hassan Mkamba, Rose Mmari and Rehmant Songoro. We acknowledge the support of the Ifakara Health Institute and Swiss Tropical and Public Health Institute for their continuous support throughout all the stages of this study. The study received funding partly from International Ford Scholarships and the Swiss Tropical and Public Health Institute.

\section{References}

Assefa, S., Erko, B., Medhin, G., Assefa, Z. \& Shimelis, T. (2009) Intestinal parasitic infections in relation to HIV/AIDS status, diarrhea and CD4 T-cell count. BMC infectious Disease, 9, 155.

Beck, D.L., Dogan, N., Maro, V., Sam, N.E., Shao, J. \& Houpt, E.R. (2008) High prevalence of Entamoeba moshkovskii in a Tanzanian HIV population. Acta Tropica $107,48-49$.

Bentwich, Z., Maartens, G., Torten, D., Lal, A.A. \& Lal, R.B. (2000) Concurrent infections and HIV pathogenesis. AIDS 14, 2071-2081.

Borkow, G. \& Bentwich, Z. (2006) HIV and helminth co-infection: is deworming necessary? Parasite immunology 28), 605-612.

Concha, R., Harrington, W.J. \& Rogers, A.I. (2005) Intestinal strongyloidiasis: recognition, management, and determinants of outcome. J Clin Gastroenterol 2005 Mar, 39(3):203-11. 
Eziefula, A.C. \& Brown, M., 2008. Intestinal nematodes: disease burden, deworming and the potential importance of co-infection. Current Opinion in Infectious Diseases $21,516$.

French, N., Nakiyingi, J., Lugada, E., Watera, C., Whitworth, J.A. \& Gilks, C.F. (2001) Increasing rates of malarial fever with deteriorating immune status in HIV-1-infected Ugandan adults. AIDS 15, 899-906.

Goujard, C., Bonarek, M., Meyer, L., Bonnet, F., Chaix, M., Deveau, C., Sinet, M., Galimand, J., Delfraissy, J.F., Venet, A., Rouzioux, C. \& Morlat, P. ( 2006) CD4 cell count and HIV DNA level are independent predictors of disease progression after primary HIV type 1 infection in untreated patients. Clinical Infectious Diseases 42, 709-715.

Grant, A.D., Djomand, G., Smets, P., Kadio, A., Coulibaly, M., Kakou, A., Maurice, C., Whitaker, J.P., Sylla-Koko, F., Bonard, D., Wiktor, S.Z., Hayes, R.J., De Cock, K.M. \& Greenberg, A.E. (1997) Profound immunosuppression across the spectrum of opportunistic disease among hospitalized HIV-infected adults in Abidjan, Cote d'Ivoire. AIDS 11, 1357-1364.

Harris, R.J., Sterne, J.A., Abgrall, S., Dabis, F., Reiss, P., Saag, M., Phillips, A.N., Chêne, G., Gill, J.M., Justice, A.C., Rockstroh, J., Sabin, C.A., Mocroft, A., Bucher, H.C., Hogg, R.S., Monforte, A.D. \& May, M., Egger, M. (2008) Prognostic importance of anaemia in HIV type-1-infected patients starting antiretroviral therapy: collaborative analysis of prospective cohort studies. Antiviral Therapy 13, 959-967. Hughes, G.J., Willey. S.J., Cochrane, A., Leen, C., Bell, J.E., Simmonds, P. (2007) Virus immunocapture provides evidence of CD8 lymphocyte-derived HIV-1 in vivo. AIDS 21, 1507-1513.

Kamya, M.R. Gasasira, A.F., Yeka, A., Bakyaita, N., Nsobya, S.L., Francis, D., Rosenthal, P.J., Dorsey, G. \& Havlir, D. (2006) Effect of HIV-1 infection on antimalarial treatment outcomes in Uganda: a population-based study. Journal of Infectious Diseases 193, 9-15.

Kaplan, J.E., Hu, D.J., Holmes, K.K., Jaffe, H.W., Masur, H., De Cock, K.M. (1996) Preventing opportunistic infections in human immunodeficiency virus-infected persons: implications for the developing world. American Journal of Tropical Medicine and Hygiene 55, 1-11.

Karp, C.L. \& Auwaerter, P.G. (2007) Coinfection with HIV and tropical infectious diseases. II. Helminthic, fungal, bacterial, and viral pathogens. Clinical Infectious Diseases 45, 1214-1220.

Karp, C.L. \& Neva, F.A. (1999) Tropical infectious diseases in human immunodeficiency virus-infected patients. Clinical Infectious Diseases 28, 947-963.

Kelly, P., Todd, J., Sianongo, S., Mwansa, J., Sinsungwe, H., Katubulushi, M., Farthing, M.J. \& Feldman, R.A. (2009) Susceptibility to intestinal infection and diarrhoea in Zambian adults in relation to HIV status and CD4 count. BMC Gastroenterology 9, 7 . 
Knuchel, M.C., Jullu. B., Shah, C., Tomasik, Z., Stoeckle, M.P., Speck, R.F., Nadal, D., Mshinda, H., Böni, J., Tanner, M. \& Schüpbach, J. (2007) Adaptation of the Ultrasensitive HIV-1 p24 Antigen assay to dried blood spot testing. Journal of Acquired Immune Deficiency Syndrome 44, 247-253.

Lewthwaite, P., Gill, G.V., Anthony, H.C. \& Beeching, N.J. (2005) Gastrointestinal parasites in the immunocompromised. Current Opinion in Infectious Diseases 18, 427.

Marques, N., Cabral, S., Sa, R., Coelho, F., Oliveira, J., Saraiva da Cunha, J.G. \& Silvestre, M.A. (2007) Visceral leishmaniasis and HIV infection in the HAART era]. Acta Medica Portuguesa 20, 291-298.

Marti, H. \& Escher, E. (1990) SAF--an alternative fixation solution for parasitological stool specimens. Schweizerische Medizinische Wochenschrift 120, 1473-1476.

Martin-Blondel, G., Soumah, M., Camara, B., Chabrol, A., Porte, L., Delobel, P., Cuzin, L., Berry, A., Massip, P., Marchou, B. (2009) Impact of malaria on HIV infection. Medecine et Maladies Infectieuses. Available at: http://www.ncbi.nlm.nih.gov/pubmed/19951829 (Accessed May 13, 2010).

Masur, H., Holmes, K.K. \& Kaplan, J.E. (2000) Introduction to the 1999 USPHS/IDSA guidelines for the prevention of opportunistic infections in persons infected with human immunodeficiency virus. Clinical Infectious Diseases 30 (Suppl 1), S1-4.

Modjarrad, K. Zulu, I., Redden, D.T., Njobvu, L., Freedman, D.O. \& Vermund, S.H. (2005) Prevalence and predictors of intestinal helminth infections among human immunodeficiency virus type 1-infected adults in an urban African setting. American Journal of Tropical Medicine and Hygiene 73, 777-782.

Nielsen, N.O., Friis, H., Magnussen, P., Krarup, H., Magesa, S. \& Simonsen, P.E. (2007) Co-infection with subclinical HIV and Wuchereria bancrofti, and the role of malaria and hookworms, in adult Tanzanians: infection intensities, CD4/CD8 counts and cytokine responses. Transactions of the Royal Society of Tropical Medicine and Hygiene 101, 602-612.

Paton, N.I., Sangeetha, S., Earnest, A. \& Bellamy, R. (2006) The impact of malnutrition on survival and the CD4 count response in HIV-infected patients starting antiretroviral therapy. HIV Medicine 7, 323-330.

Reeves, J.D. \& Piefer, A.J. (2005) Emerging drug targets for antiretroviral therapy. Drugs 65, 1747-1766.

Schüpbach, J. (2003) Viral RNA and p24 antigen as markers of HIV disease and antiretroviral treatment success. International Archives of Allergy and Immunology 132, 196-209.

Secor, W.E. (2006) Interactions between schistosomiasis and infection with HIV-1. Parasite immunology 28, 597-603.

Shapira-Nahor, O., Kalinkovich, A., Weisman, Z., Greenberg, Z., Nahmias, J., Shapiro, M., Panet, A. \& Bentwich, Z. (1998) Increased susceptibility to HIV-1 infection of peripheral blood mononuclear cells from chronically immune-activated individuals. AIDS 12, 1731-1733. 
Tarimo, D.S., Killewo, J.Z., Minjas, J.N. \& Msamanga, G.I. (1996) Prevalence of intestinal parasites in adult patients with enteropathic AIDS in north-eastern Tanzania. East African Medical Journal 73, 397-399.

Whitworth, J., Morgan, D., Quigley, M., Smith, A., Mayanja, B., Eotu, H., Omoding, N., Okongo, M., Malamba, S. \& Ojwiya, A. (2000) Effect of HIV-1 and increasing immunosuppression on malaria parasitaemia and clinical episodes in adults in rural Uganda: a cohort study. The Lancet 356 (9235), 1051-1056.

Wolday, D., Mayaan, S., Mariam, Z.G., Berhe, N., Seboxa, T., Britton, S., Galai, N., Landay, A. \& Bentwich, Z. ( 2002) Treatment of intestinal worms is associated with decreased HIV plasma viral load. Journal of Acquired Immune Deficiency Syndromes 31, 56-62.

**

\begin{abstract}
Untreated tropical parasitic co-infections appear to speed the progression of HIV-1 disease. However, to date, there have been few studies conducted in resource limited settings to ascertain the interaction of parasitic co-infection where HIV/AIDS management largely depends on CD4+ T lymphocyte cells counts and WHO clinical staging. This study aimed to determine the prevalence of parasites, their association with CD4+ T lymphocyte cells changes and clinical manifestation of HIVinfection in patients attending HIV/AIDS management clinics in Tanzania. Adult HIV-infected patients registering for the first time at HIV/AIDS management clinics were recruited; with physical examination and laboratory tests performed at baseline and after 6 months. Patients were assigned a clinical stage and screened for helminths and Plasmodium sp. co-infection, CD4+ T lymphocyte cells, haemoglobin and HIV-1 p24 antigen. Of the 421 HIV-1 infected patients studied, 198 (47.0\%) were coinfected with one or more parasites. Of those studied, 93/421(22.1\%) had helminth only co-infection, and 50/421(12.9\%) had Plasmodium sp only co-infection. Mixed Plasmodium sp and helminth coinfection was diagnosed in 55/421(13.0\%) patients. Helminths frequently diagnosed included: hookworm 65/421(15.4\%), Schistosomiasis 49/421(11.6\%), Strongyloides stercoralis 57/421(13.5\%), and Ascaris lumbricoides 54/421(12.8\%). No statistical association was found between CD4+ T lymphocyte

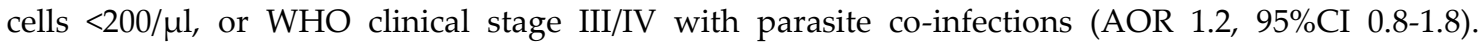
Anaemia was common in parasite co-infected patients (32.8\% vs 18.8\%). Parasite co-infection was associated with risk of anaemia (AOR 2.1, 95\%CI 1.3-3.2). In multivariable logistic regression analysis, baseline CD4+ T lymphocyte cells $<200 / \mu 1$ was significantly associated with CD4+ T lymphocyte cells $<200 / \mu \mathrm{l}$ (AOR 2.4, 95\%CI 1.3-4.7) at six months. HIV-1 P24 antigen mean concentration was higher in parasite co-infected patients (ranges 47.6 to 56.9) as compared to patients without parasite coinfection (5.5). We have looked at one set of parasites and found high prevalence of malaria and helminth co-infection in HIV-infected individuals. Given the available reports on health impacts of helminth co-infection in HIV/AIDS patients and the anecdotal reports of helminth's health effects in HIV-uninfected persons, helminths and other prevalent parasites should not be ignored in HIV/AIDS programs. Based on local helminth epidemiology and HIV-infected cohort specific helminths coinfection prevalence data, mass treatment of soil transmitted helminths can be incorporated into HIV/AIDS management programmes.
\end{abstract}

Key words: parasites, HIV-1, co-infection, patients, Tanzania

\title{
Introduction
}


HIV-infection and AIDS in sub-Saharan Africa present with diverse clinical characteristics reflecting the variety of prevalent endemic diseases within the region. More than 100 different disease-causing agents are found in the region including viruses, bacteria, fungi, protozoa, helminths and arthropods (Karp \& Auwaerter, 2007). A relatively small proportion of these pathogens cause the majority of serious health complications experienced by HIV-infected persons (Kaplan et al., 1996). Distribution of these pathogens is geographically sensitive to favourable environments, characterized by social behaviours and ecological factors which affect the risk of transmission (Masur et al., 2000).

Concurrence of HIV and tropical infections affect each other mutually. HIV in patients with parasite infection alters the natural clinical progression of the parasitic diseases, and reduces the efficacy of parasitic treatment (Marques et al., 2007) (Kamya et al., 2006). HIV-1 compromises the cellular immune system by destroying CD4+ T lymphocyte cells and macrophages; (Reeves \& Piefer, 2005) thus reducing the immune system's ability to resist infection from regionally endemic pathogens (Hughes et al., 2007). HIV-infected persons are susceptible to new infection and reactivation of (Reeves \& Piefer, 2005) latent infections (Karp \& Auwaerter, 2007). As a result, HIV-immunosuppression facilitates infections, increases the severity of infection, changes disease presentation and complicates treatment (Karp \& Neva, 1999). Of particular importance is the increased risk of parasitaemia and clinical malaria in semi-immune HIV-infected adults in malaria endemic regions (French et al., 2001). In addition to HIV-effects on susceptibility and pathogenesis of tropical diseases, people living with tropical infections are at increased risk for HIV-infection and unfavourable disease progression (Bentwich et al., 2000).

Health effects of parasitic co-infections in HIV-infected persons marked HIV/AIDS clinical manifestations in the early decades of the HIV epidemic. For example, protozoa infections caused chronic diarrhoea which resulted in wasting (slim disease), chronic fever without an obvious source, and pulmonary disease syndromes; all symptoms used to classify AIDS in sub Saharan Africa (Kaplan et al., 1996; Grant et al., 1997). There is evidence that helminth species specifically alter HIV disease progression. Interaction of Schistosome and HIV-infections with host CD4+ T lymphocyte cells leads to bi-directional effects, which are different from sequelae caused by an infectious agent alone (Secor, 2006). Helminth infections leads to greater HIV-replication and disease progression, through immune activation of cellular mechanisms rendering the CD4+ T lymphocyte cells susceptible to HIV-infection and resulting in increased viral load (Shapira-Nahor et al., 1998). High viral load is associated with rapid CD4+ T lymphocyte cells death and disease progression to AIDS (Borkow \& Bentwich, 2006). Untreated Strongyloides stercoralis causes hyper-infection syndrome in immunosuppressed patients after initiation of antiretroviral therapy (ART). It is difficult to distinguish between the clinical manifestation of strongyloidiasis hyperinfection syndrome and the immune-reconstitution syndrome induced by HAART in patients with CD4+ T lymphocyte cells $<200 / \mu \mathrm{l}$; both conditions are fatal without proper management (Concha et al., 2005; Lewthwaite et al., 2005).

Although scientists still debate on the survival benefit of routine screening and treatment for helminths and other parasitic infection in HIV-infected patients, helminths and malaria infections continue to cause morbidity and aggravated mortality (French et al., 2001). Treatment of parasitic infections could provide an immediate benefit in areas where both HIV-1 and helminths are prevalent. 
Tanzania has overlapping, high prevalence rates of HIV and parasitic infections (Beck et al., 2008). Scaling up of HIV and AIDS management services has become wellestablished and widely available, allowing quality of care to become increasingly important to investigate and improve. This opens the door for identifying co-infections with latent helminths and malaria as important areas to investigate.

Untreated tropical parasitic co-infections appear to speed the progression of HIV-1 disease. However, to date, there have been few studies conducted in resource limited settings to ascertain the interaction of parasitic co-infection where HIV/AIDS management largely depends on CD4+ T lymphocyte cells counts and WHO clinical staging guidelines. This study aimed to determine the prevalence of parasites, their association with CD4+ T lymphocyte cells changes and clinical classification of HIV-infection in patients attending management clinics in Tanzania.

\section{Materials and Methods}

\section{Study area}

The study was conducted at Tumbi Hospital (urban) and Chalinze Health Centre (periurban) in Pwani Region, Eastern Tanzania between April 2008 and March 2009. Tumbi Regional Hospital is located $40 \mathrm{~km}$ from Dar es Salaam, the commercial capital of Tanzania. The hospital has a bed capacity of 200 beds and serves as a regional specialized Hospital. Chalinze Health Centre is located $70 \mathrm{~km}$ from Tumbi Hospital located at the Regional capital of Pwani. Both heath facilities provide services to a mixture of patients from urban and rural villages. Most residents of Chalinze reside in rural villages and generate income from farming and trading of different types of goods.

\section{Study population}

We studied newly enrolled adult HIV-infected patients attending HIV/AIDS management services at Tumbi Hospital and Chalinze Health Centre. Patients residing in the catchments areas of both Tumbi Hospital and Chalinze Health Centre were selected for inclusion in the study. Exclusion criteria included: less than 18 years of age, pregnancy, and patients with obviously severe disease conditions (i.e. Tuberculosis, Cryptococcus meningitis, Pneumonia and generalized Kaposi's sarcoma) or necessary transfer to another clinic.

A study nurse identified eligible patients after completing routine clinic registration procedures. Patients were individually screened for eligibility after which a standardized informed consent was administered. Consenting patients were assigned a study identification number which was affixed to the clinic card and case file. The patient was then referred to a study clinician for clinical examination. Study clinicians recorded patients' clinical history, performed physical examinations and staging of HIV according to the Tanzania and WHO clinical guidelines for management of HIV and AIDS. Patients were referred to the laboratory for sample collection.

\section{Specimen collection and processing}

Blood specimens were collected in EDTA tubes for enumeration of CD4+ T lymphocyte cells, haemoglobin and malaria smear, while part of the sample was frozen and shipped to Ifakara Health Institute laboratory for HIV-1 P24 plasma ELISA assays. Fresh stool samples were collected in sterilized plastic containers, preserved in 10\% formalin and examined within 24 
hours by formol-ether concentration techniques (Marti \& Escher, 1990). In stool samples found to contain ova or larvae, intensity of infection was estimated by quantitative analysis of the egg burden according to the Kato-Katz thick-smear technique. Patients who could not produce stool during the clinic visit were provided with sterile plastic containers and asked to bring a fresh stool specimen on their next visit. Sterile plastic containers were also used to collect a clean-catch urine specimen.

Malaria, urine and haemoglobin results were returned to the patient on the same day, while other test results were available at subsequent visits. Study patients were scheduled a follow-up visit 14 days after initial enrolment to complete ART eligibility, counselling and other assessments. Patients received standard treatment according to infections diagnosed: malaria was treated using Coartem (artemether $20 \mathrm{mg} / \mathrm{lumefantrine}$ $120 \mathrm{mg}$ ), intestinal helminths were treated with Albendazole (400mg day one and 200mg 2 subsequent days), and Schistosomiasis was treated with Praziquantel (40mg/kg divided into 2 doses, 6 hours apart). After the $14^{\text {th }}$ day visit, study patients were scheduled to follow-up with monthly visits, regardless of ART status. The $6^{\text {th }}$ month follow-up visit was scheduled for patients during their subsequent clinic visits. Clinical examination and laboratory procedures performed at initial enrolment were repeated at the $6^{\text {th }}$ month visit.

Specimens for CD4+ T lymphocyte cells, haemoglobin, malaria, sputum, and urine and stool samples were analyzed at Tumbi Hospital laboratory. CD4+ T lymphocyte cells analysis was performed using automated FACS count (BD Biosciences, California, USA). Biochemistry and haematological parameters were analyzed using a Biochemical analyzer (Italy) and haematological analyzer (Pentra 80, France) respectively. Malaria smears were Giemsa stained and microscopically examined for parasitaemia. Sputum specimens were stained using Ziehl-Neelsen technique and examined for mycobacterium tuberculosis.

Stool samples were fixed using sodium acetate-acetic acid-formalin (SAF) solution and microscopically examined for parasites and helminths. A sample of the fresh stool was cultured in Xylose Lysine Deoxycholate Agar (XLD) media for Salmonella and Shigella. Direct microscopic examination was performed on urine samples. HIV-1 P24 sample analysis was conducted with the Ifakara Health Institute's adapted PerkinElmer Life Sciences "P24 Ultra sensitive Assay Protocol" (ELAST® kit) (Knuchel et al., 2007)].

\section{Data analysis}

Data was entered into Microsoft ®Access, and analyzed using Stata Intercooled version 9. Standard definitions of severe immunological suppression were used to describe the magnitude of CD4+ T lymphocyte cells decline. Patients with CD4+ T lymphocyte cells counts below and above 200 cells/ $\mu$ l were categorized as severely and moderately immunosuppressed, respectively. Logistic regression models were used to generate odds ratios associated with CD4+ T lymphocyte cells $<200 / \mu 1$. An attempt was made to compare patient groups according to the specific helminth infection, but was limited by small samples of each patient helminths infected group. .

\section{Ethical considerations}

The study received scientific and ethical approval from the Muhimbili University of Health and Allied Sciences Research Ethics Review Board (Ref.No.MU/RP/AEC/Vol.XII/58). Permission was granted by the appropriate Region, District and hospital authorities. 
Informed consent for participation was obtained from patients using Kiswahili, the local language. 


\section{Results}

\section{Baseline characteristics}

A total of 464 subjects were enrolled into the study between April 2008 and March 2009, with 421 patients completing baseline data for analysis. Forty three patients were excluded from the analysis because of insufficient samples for parasitological diagnosis. Patients excluded did not differ from the remaining patients in terms of socio-demographic characteristics, CD4 cell counts and clinical presentation at the time of enrolment.

The mean age of participants was 35.7(SD 34.6 to 36.9) years and the mean body weight was $51.6 \mathrm{~kg}$ (SD 50.0 to 53.1). The majority of patients were women $261 / 421(62 \%)$. In total $272 / 421(64.6 \%)$ of patients were living in rural areas with a high proportion of all patients having completed primary education 336/421 (80\%). There were no remarkable differences between patient groups. The majority of patients used pit latrines for excreta disposal and obtained water for domestic use from mixed sources (

) .

Table 1: Baseline demographic, social and clinical characteristics of patients by parasites status

\begin{tabular}{|c|c|c|c|c|c|}
\hline Characteristics & Response & $\begin{array}{l}\text { Patients } \\
\text { without } \\
\text { parasites } \\
\mathrm{N}=223\end{array}$ & $\begin{array}{l}\text { Patients } \\
\text { with } \\
\text { helminths } \\
\text { only } N=93\end{array}$ & $\begin{array}{l}\text { Patients } \\
\text { with } \\
\text { malaria } \\
\text { only } N=50\end{array}$ & $\begin{array}{l}\text { Mixed } \\
\text { helminths } \\
\text { and malaria } \\
\mathrm{N}=55\end{array}$ \\
\hline Weight-kg mean(SD) & & $51.4(1.3)$ & $49.2(1.2)$ & $52.5(1.2)$ & $48.7(1.2)$ \\
\hline $\begin{array}{l}\text { Age in years, mean } \\
\text { (SD) }\end{array}$ & & $35.7(1.3)$ & $36.0(1.3)$ & $35.5(1.3)$ & $34.7(1.3)$ \\
\hline \multirow[t]{2}{*}{ Sex n $(\%)$} & Women & $147(65.9)$ & $51(54.8)$ & $30(60.0)$ & $33(60.0)$ \\
\hline & Men & $76(34.1)$ & $42(45.2)$ & $20(40.0)$ & $22(40.0)$ \\
\hline \multirow[t]{2}{*}{$\begin{array}{l}\text { Residential status } n \\
(\%)\end{array}$} & Rural & $146(65.5)$ & $57(61.3)$ & $28(56.0)$ & $41(74.6)$ \\
\hline & Urban & $77(34.5)$ & $36(38.7)$ & $22(44.0)$ & $14(25.4)$ \\
\hline \multirow[t]{3}{*}{ Education n (\%) } & Incomplete primary & $28(12.6)$ & $8(8.7)$ & $7(14.0)$ & $6(10.9)$ \\
\hline & Primary & $173(77.6)$ & $78(84.8)$ & $41(82.0)$ & $44(80.0)$ \\
\hline & College & $22(9.8)$ & $6(6.5)$ & $2(4.0)$ & $5(9.1)$ \\
\hline \multirow{4}{*}{$\begin{array}{l}\text { Marital status } \mathrm{n}(\%) \\
\text { Married/cohabiting } \\
\text { Single } \\
\text { Widowed } \\
\text { Separated/Divorced }\end{array}$} & Married/cohabiting & $104(46.6)$ & $35(38.0)$ & $24(48.0)$ & $21(38.2)$ \\
\hline & Single & $66(29.6)$ & $35(38.0)$ & $12(24.0)$ & $21(38.2)$ \\
\hline & Widowed & $47(21.1)$ & $16(17.4)$ & $10(20.0)$ & $6(10.9)$ \\
\hline & Separated/Divorced & $6(2.7)$ & $6(6.6)$ & $4(8.0)$ & $7(12.7)$ \\
\hline \multirow{3}{*}{$\begin{array}{l}\text { Source of } \\
\text { supply } n(\%)\end{array}$} & Home tap & $13(5.8)$ & $4(4.3)$ & $6(12.0)$ & $5(9.1)$ \\
\hline & Well or river & $43(19.3)$ & $19(20.7)$ & $9(18.0)$ & $13(23.6)$ \\
\hline & Mixed & $167(74.9)$ & $69(75.0)$ & $35(70)$ & $37(67.3)$ \\
\hline \multirow{3}{*}{$\begin{array}{l}\text { Types of latrine } n \\
(\%)\end{array}$} & Pit & $170(76.2)$ & $73(78.5)$ & $42(84.0)$ & $42(76.4)$ \\
\hline & Flush & $22(9.9)$ & $11(11.9)$ & $7(14.0)$ & $10(18.2)$ \\
\hline & No latrine & 31 (13.9) & $8(8.7)$ & $1(2.0)$ & $3(5.4)$ \\
\hline
\end{tabular}

Among the $421 \mathrm{HIV}-1$ infected patients included in data analysis at initial assessment, 198 $(47 \%)$ were found to be co-infected with one or more parasites. Helminth only co-infection 
was diagnosed in 93/421 (22.1\%) patients, while 50/421 (11.9\%) patients exhibited Plasmodium sp. parasitaemia but no helminth co-infection. Mixed Plasmodium sp and helminth co-infection was diagnosed in 55/421 (13.1\%) patients ( ) .

Plasmodium was the most common parasite isolated 105/421(24.9\%). Of the helminths diagnosed, most frequently detected were: hookworm 65/421(15.4\%), Schistosome 49/421(11.6\%), Strongyloides stercoralis 57/421(13.5\%), and Ascaris lumbricoides 54/421(12.8\%). Parasite infected patients had one and sometimes up to five types of parasites. Multiple parasites were diagnosed in $89 / 421(21.1 \%)$ patients. Only one patient was found to harbour all five parasites (Table 2).

Table 5: Number of parasites infections, WHO stage and mean HIV-P24 of HIV/AIDS patients grouped according to CD4+ $\mathrm{T}$ lymphocyte cells categories

\begin{tabular}{|c|c|c|c|c|c|c|c|}
\hline $\begin{array}{l}\text { CD4+ } \quad T \\
\text { lymphocyte }\end{array}$ & $\begin{array}{l}\text { Number } \\
\text { individual }\end{array}$ & of & site & per & WHO Stage & & HIV-1 P24 \\
\hline cells category & 0 & 1 & 2 & $\geq 3$ & I/II & III/IV & Mean (SD) \\
\hline 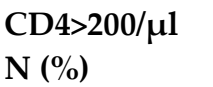 & $97(43.5)$ & $48(44.0)$ & $17(28.8)$ & 11(36.7) & $100(54.4)$ & $73(30.8)$ & $5.4(20.9)$ \\
\hline 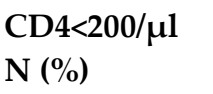 & $126(56.5)$ & $61(56.0)$ & $42(71.2)$ & $19(63.3)$ & $84(45.6)$ & $164(69.2)$ & $30.4(16.2)$ \\
\hline Total & $223(100)$ & 109(100) & $59(100)$ & 30(100) & 184(100) & 237(100) & $15.3(20.3)$ \\
\hline
\end{tabular}

${ }^{*}$ Test for trend across ordered groups: $Z=1.69, p=0.09$

At the time of enrolment into the study, more than half of the HIV+ patients were in clinical stages III/IV and had CD4+Tcells <200/ $\mu$ l (237/421(56.3\%) and 248/421(58.9\%) respectively. The mean HIV-1 p24 concentration was 15.3 (SD 20.3). A higher HIV-1 p24 concentration was found in patients with lower CD4+ T lymphocyte cells counts and WHO clinical stages III/IV. An additional finding was the high concentration of HIV-P24 antigens in patients with parasite co-infection (Helminths $47.6 \mathrm{pg} / \mathrm{ml}$, Malaria $49.7 \mathrm{pg} / \mathrm{ml}$ and mixed helminths $/$ malaria $56.9 \mathrm{pg} / \mathrm{ml})$ compared to patients without parasites $(5.5 \mathrm{pg} / \mathrm{ml})$. High concentration of HIV-1 P24 is associated with rapid HIV-1 disease progression.

\section{Effect of parasite co-infection on CD4+Tcells, anaemia and WHO clinical stages}

Overall, parasite infected patients had lower CD4+ T lymphocyte cells counts than parasite free patients, but this was not statistically significant (Table 6). Multiple infection was

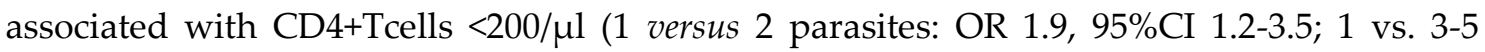
parasites: OR 2.3, 95\%CI 1.5-10.7) than one parasite co-infection. The test for trend across ordered groups provided some evidence that the number of parasites is associated with low $\mathrm{CD} 4+\mathrm{T}$ lymphocyte cells counts. However, the result was only marginally significant $(\mathrm{Z}=$ 1.69, $P=0.09$ ) (Table 2).

The associations of CD4+ T lymphocyte cells $<200 / \mu 1$, anaemia (haemoglobin $<8.0 \mathrm{~g} / \mathrm{dl}$ ) and WHO clinical stage III/IV were examined in patients with and without parasite coinfections (Table 3). No statistically significant differences were observed between patients with and without parasite co-infection in association with CD4+ T lymphocyte cells $<200 / \mu 1$. The adjusted odds ratios for parasite co-infected patients was less than one, except for 
patients with mixed malaria and helminths, any helminths, strongyloides and Ascaris lumbricoides only infections ( $\mathrm{OR}=1.2,1.6,1.5$ and 2.2, respectively).

Table 6: Univariate analysis of the association between parasites and clinical parameters before initiation of ART and other treatment of HIV and AIDS patients

\begin{tabular}{|c|c|c|c|c|c|c|}
\hline \multirow[t]{2}{*}{$\begin{array}{l}\text { Infection } \\
\text { status }\end{array}$} & \multicolumn{2}{|c|}{$\begin{array}{l}\text { CD4+ T lymphocyte cells } \\
\text { count } / \mu \mathrm{l}\end{array}$} & \multicolumn{2}{|c|}{ Haemoglobin g/dl } & \multicolumn{2}{|c|}{ WHO clinical stage } \\
\hline & CD4<200 (\%) & $\begin{array}{l}\text { AOR* }^{*} \\
(95 \% \mathrm{CI})\end{array}$ & $\mathrm{HB}<8.0(\%)$ & $\begin{array}{l}\text { AOR* }^{*} \\
(95 \% \mathrm{CI})\end{array}$ & III/IV (\%) & $\begin{array}{l}\text { AOR* }^{*} \\
(95 \% \mathrm{CI})\end{array}$ \\
\hline No infection & $126 / 223(56.5)$ & Reference & $42 / 223(18.8)$ & Reference & $121 / 223(54.3)$ & Reference \\
\hline Any parasites & $122 / 198(61.1)$ & $1.2(0.8-1.8)$ & $64 / 198(32.5)$ & $2.1(1.3-3.2)$ & $116 / 198(58.6)$ & $1.2(0.8-1.8)$ \\
\hline Malaria only & $27 / 50(54.0)$ & $0.9(0.5-1.7)$ & $12 / 50(24.0)$ & $1.4(0.7-3.0)$ & $25 / 50(50.0)$ & $0.8(0.4-1.5)$ \\
\hline $\begin{array}{l}\text { Helminths+ } \\
\text { Malaria }\end{array}$ & $33 / 55(60.0)$ & $1.2(0.6-2.1)$ & $25 / 55(45.5)$ & $3.8(1.9-7.1)$ & $32 / 55(58.2)$ & $1.2(0.7-2.2)$ \\
\hline $\begin{array}{l}\text { Helminths } \\
\text { only }\end{array}$ & 62/93(66.7) & $1.6(0.9-2.6)$ & 28/93(30.1) & $1.9(1.1-3.3)$ & $59 / 93(63.4)$ & $1.5(0.9-2.5)$ \\
\hline Hookworm & $7 / 15(46.7)$ & $0.6(0.6-1.8)$ & $5 / 15(33.3)$ & $2.1(0.9-6.7)$ & $10 / 15(66.7)$ & $1.6(0.5-4.8)$ \\
\hline Schistosome & $6 / 13(46.2)$ & $0.7(0.2-2.2)$ & $2 / 13(15.4)$ & $0.9(0.2-4.5)$ & $5 / 13(38.5)$ & $0.6(0.2-1.8)$ \\
\hline $\begin{array}{l}\text { Strongyloides } \\
\text { stercoralis }\end{array}$ & $9 / 14(75.0)$ & $1.5(0.5-4.5)$ & $1 / 14(7.1)$ & $0.4(0.1-2.9)$ & $9 / 14(64.3)$ & $1.5(0.5-4.7)$ \\
\hline $\begin{array}{l}\text { Ascaris } \\
\text { lumbricoides }\end{array}$ & $11 / 15(73.3)$ & $2.2(0.8-7.2)$ & 8/15(53.3) & $5.3(1.8-15.7)$ & $10 / 15(66.7)$ & $1.7(0.6-5.2)$ \\
\hline
\end{tabular}

*Odds ratios adjusted to age and sex

The prevalence of anaemia was higher $64 / 198(32.5 \%)$ in parasite co-infected when compared to patients without co-infection $42 / 223(18.8 \%)$. Parasite co-infection was associated with significant risk of anaemia (AOR 2.1, 95\%CI 1.3 to 3.2). The odds of having anaemia were high in patients with mixed helminths and malaria infection, increased by a factor more than $3(\mathrm{AOR}=3.8,95 \%$ CI 1.9 to 7.1 ) when compared to patients without co-infection. There was a strong association between Ascaris lumbricoides and anaemia (AOR=5.3, 95\%CI 1.8 to 15.7). Patients with any helminth infection had almost two times the odds of having anaemia (AOR 1.9, 95\%CI (1.1-3.3). Similarly, patients co-infected with hookworm had two times the odds (AOR=2.1, 95\% CI 0.9-6.7) of having severe anaemia. However, this association was not statistically significant. The associations between either Strongyloides stercoralis or schistosomiasis and anaemia were affected by small sample sizes, and did not demonstrate any statistically significant association with anaemia (AOR 0.4, 95\%CI 0.1-2.9, AOR 0.9, 95\%CI 0.2-4.5 respectively). However, it is known that Schistosoma haematobium causes moderate anaemia. Neither multiple co-infection with any parasites (AOR 1.2, 95\%CI 0.8-1.8) nor with single infection (AOR 0.8-1.7, 95\% CI 0.4-5.2) was significantly associated with WHO clinical stages III/IV.

\section{Changes in CD4+ T lymphocyte cells counts after treatment}

Of the 421 patients included in baseline analysis, one patient died and 18 patients were infected or re-infected with parasites during the 6 months follow-up period. At the completion of the 6 month follow-up, 196 (98.9\%) of patients with parasites and $222(99.6 \%)$ of patients without parasites at enrolment had complete data for analysis. In total 312(74.1\%) patients were started on ART during the period. We observed an increase in CD4+ T lymphocyte cells counts at six months in the majority of ART patients both with and without 
parasites. Patients with parasites at baseline 151/196(77.0\%) experienced an increase in CD4+ T lymphocyte cells counts; the majority being those taking ART treatment 129/151(85.4\%). Similarly, for patients without parasite co-infection, 147/222(66.2\%) CD4+ T lymphocyte cells counts increased $125 / 147(85.0 \%)$ with the majority being patients on ART treatment. The mean CD4+ T lymphocyte cells count increase found was 111.6(9.0) and 108.6(8.2) in patients with and without parasite infection at baseline, respectively.

Table 7: Changes in CD4+ T lymphocyte cells counts between baseline and after six months of HIV/AIDS patients

\begin{tabular}{|c|c|c|c|c|c|c|c|c|c|}
\hline \multirow{3}{*}{$\begin{array}{l}\text { ART } \\
\text { status }\end{array}$} & \multicolumn{4}{|c|}{ With parasites at Baseline $\mathrm{N}=196$} & \multicolumn{4}{|c|}{ No parasites at Baseline $\mathrm{N}=\mathbf{2 2 2}$} & \multirow{3}{*}{$\begin{array}{l}\text { New } \\
\text { /re- } \\
\text { infection }\end{array}$} \\
\hline & \multicolumn{2}{|c|}{ Mean CD4 increase } & \multicolumn{2}{|c|}{ Mean CD4 decrease } & \multicolumn{2}{|c|}{ Mean CD4 increase } & \multirow{2}{*}{$\begin{array}{l}\text { Mean } \\
\text { decrease } \\
\text { N (\%) }\end{array}$} & CD4 & \\
\hline & $\mathbf{N}(\%)$ & $\begin{array}{l}\text { Mean } \\
\text { (SD) }\end{array}$ & $\mathbf{N}(\%)$ & $\begin{array}{l}\text { Mean } \\
\text { (SD) }\end{array}$ & N (\%) & $\begin{array}{l}\text { Mean } \\
\text { (SD) }\end{array}$ & & $\begin{array}{l}\text { Mean } \\
\text { (SD) }\end{array}$ & \\
\hline ART & $129(85.4)$ & 129.9(1.9) & $19(42.2)$ & $54.7(2.3)$ & $125(85.0)$ & $118.4(1.9)$ & $23(30.7)$ & $47.5(2.9)$ & $16(88.9)$ \\
\hline $\begin{array}{l}\text { Not } \\
\text { on } \\
\text { ART }\end{array}$ & $22(14.6)$ & $60.2(2.8)$ & $26(57.8)$ & $181.4(2.1)$ & $22(14.9)$ & $66.7(2.5)$ & $52(69.3)$ & $157.8(2.9)$ & $2(11.1)$ \\
\hline Total & 151(100) & $111.6(2.2)$ & $45(100)$ & $109.3(2.7)$ & $147(100)$ & $108.6(2.1)$ & $75(100)$ & $109.2(3.4)$ & $18(100)$ \\
\hline
\end{tabular}

The CD4+ T lymphocyte cells counts decreased between enrolment and 6 month follow-up in $45 / 196(22.9 \%)$ patients with parasites and 75/222(33.7\%) patients without parasites. The mean CD4+ T lymphocyte cells count decrease was 109.3(SD 14.9) and 101.2(SD 29.9) in patients with and without parasites, respectively. A statistically significant difference was observed between patients with parasite co-infection who experienced CD4+ T lymphocyte cells count increase and those whose CD4+ T lymphocyte cells count decreased $(p=0.001)$. Similar results were observed in patients without parasites.

Table 8: Multivariable Logistic Regression for predictors of CD4+ T lymphocyte cells $<200 / \mu 1$ after 6 months of follow-up of HIV and AIDS patients attended

\begin{tabular}{ll}
\hline Variables & Adjusted OR(95\%CI) \\
\hline Female & $0.9(0.6-1.4)$ \\
Baseline CD4+ T lymphocyte cells counts* & $2.4(1.3-4.7)$ \\
Baseline P24 Antigen levels & $1.0(0.9-1.1)$ \\
Baseline WHO clinical stage** & $1.0(0.7-1.6)$ \\
ART treatment & $1.3(0.6-2.6)$ \\
Helminths or malaria new/re-infection & $1.6(0.4-5.7)$ \\
\hline
\end{tabular}

*Reference category CD4+ T lymphocyte cells $>200 / \mu 1 .{ }^{* *}$ Reference category WHO clinical stage I/II

Variables known to be associated with CD4+ $\mathrm{T}$ lymphocyte cells count changes were included in multivariable logistic regression analysis. Baseline CD4+ T lymphocyte cells $<200 / \mu$ l were significantly (AOR 2.4, 95\%CI 1.3-4.7) associated with CD4+ T lymphocyte cells $<200 / \mu \mathrm{l}$ at six months (Table 8). New infections with helminths or malaria were not associated with CD4+ T lymphocyte cells <200/ $\mu$ l at six months (AOR 1.6, 95\% CI 0.4-5.7). This is probably due to low parasite infection intensity to impact CD4+ T lymphocyte cells changes within the follow up period. The impact of P24 and WHO clinical stages in 
predicting CD4+ T lymphocyte cells $<200 / \mu \mathrm{l}$ at six months was directly influenced by the initiation of ART (AOR 1.0, 95\% CI 0.7 to 1.6).

\section{Discussion}

This study found malaria and helminth co-infection more frequent in HIV-infected patients than any other parasite. The prevalence of helminths was $22.1 \%$ lower than study findings in other sub-Saharan African settings (Modjarrad et al., 2005; Assefa et al., 2009) but higher than results from other studies in rural Tanzania (Tarimo et al., 1996; Nielsen et al.,2007). We isolated hookworm, A. lumbricoides, and S. stercoralis in patients with CD4+ T lymphocyte cells $<200 \mu / 1$ rather than the common HIV-related protozoa; which marked early AIDS manifestation as causes of chronic diarrhoea. These findings may be setting specific, or a phenomenon of changing AIDS manifestation, because previous studies have reported higher prevalence rates of Cryptosporidium and Isospora belli among HIV-infected patients (Assefa et al., 2009; Kelly et al., 2009).

The prevalence of malaria co-infection in our study population was $24.9 \%$ higher than findings in previous studies of Eastern Africa (Whitworth et al., 2000; French et al., 2001). The high malaria parasitaemia in this, and other studies, points to an important interaction between HIV-1 and malaria; especially in our setting where a large population of severely immunodeficiency patients and endemic malaria coexist. Malaria is known to cause an increase in transitory viral load while HIV-1 causes more clinical malaria, higher parasitaemia and higher rates of treatment failure in co-infected patients (Kamya et al., 2006; Martin-Blondel et al., 2009).

Mixed parasite infection is common in areas where various types of parasites coexist with favourable behavioural and ecological patterns of transmission (Mboera et al. 2011). The occurrence of polyparasitism in the current study showed an inverse relationship with CD4+ T lymphocyte cells $<200 \mu / 1$. Health effects of polyparasitism depend on the types of parasite co-infection, mixed intestinal helminths and protozoa cause persistent diarrhoea and anaemia. In the case of mixed helminth and malaria infection, malaria can worsen mild anaemia due to helminths and exacerbate the HIV-infection outcome. Although this study did show a marginal statistically significant trend towards severe immunodeficiency as a result of polyparasitism; it highlights an important interaction in settings with higher prevalence of HIV-1 and parasite infection. Therefore, parasite co-infection in HIV and AIDS patients should not be ignored. Site specific assessments need to be carried out to determine the relevance and abundance of parasites to that particular region, so as to inform the basis for an intervention approach.

It is well established that CD4+ T lymphocyte cells $<200 \mu / 1$ is associated with a higher risk of opportunistic infection and poor disease progression (Goujard et al., 2006). Parasite co-infection, conversely, facilitates CD4+ T lymphocyte cells decline (Secor, 2006) through various mechanisms. This study demonstrated a statistically significant association between multiple parasite co-infections and CD4+ T lymphocyte cells <200 $\mu / 1$ before treatment, with the odds ratios showing some association. Therefore, parasite co-infection increases the risk of opportunistic infection in HIV-infected patients. Then, these study findings give the indication of a possible association in settings with high infection intensities and their impact on CD4+ T lymphocyte cells decline. 
The association of helminths and CD4+ T lymphocyte cells $<200 \mu / 1$ in this study was also affected by the low intensities of helminth infection and re-infection that occurred after treatment. An attempt was made to analyze each individual helminth species effects, but the samples were insufficient to provide a basis for inference. Parasite re-infection, and failure to control for the duration of infection, complicated the estimation of the true effects of helminths on CD4+ T lymphocyte cells decline. It is difficult to determine the duration of infection until the occurrence of CD4+ T lymphocyte cells decline. Cohort studies in different settings of high and low parasite prevalence intensities can provide adequate information on the specific interaction of helminths and HIV-infection. Health seeking behaviour is one important factor to consider as a cofounder in the role of helminths co-infection on CD4+ T lymphocyte cells decline. Late presentation is a common phenomenon in this setting, with a majority of patients seeking health care after having advanced immunodeficiency. Thus, making it difficult to establish which was the cause and effect between helminths infection and CD4+ T lymphocyte cells decline.

Our study population consisted of patients exposed to common, known risk factors for helminth infection transmission; mostly persons with only primary level education, limited access to a safe water supply; and using pit latrine, though some do not use any latrine. Therefore, human faeces pollution and high rates of helminths transmitted through soil is evident in this population. Improved sanitation, combined with de-worming programs, is most likely to eliminate helminth transmission. Although the current deworming programs are focused on school children who carry the highest burden of helminth infection, the prevalence of helminths in adults is also substantial because of transmission to the adult population (Eziefula \& Brown, 2008). Routine, mass treatment in HIV-infected persons can be beneficial and provides an appropriate alternative public health approach to routine screening and treatment; especially in regions with a high burden of helminths.

Anaemia is a common complication occurring in 20-80\% of HIV-infected patients and is also associated with rapid disease progression and mortality (Harris et al., 2008). The prevalence of anaemia in our study was significantly associated with any of the parasite coinfections. The impact of parasite co-infection on anaemia was more significant in patients with malaria and helminth polyparasitism. Such an association was not demonstrated in patients without parasite co-infection. HIV-infection can lead to anaemia in many ways in HIV-infected patients (Paton et al., 2006). Our results show the additive effects of parasite coinfection on other causes of anaemia in HIV-infected patients. In areas where HIV-infection, helminths and anaemia are prevalent; the interaction of anaemia and helminths or malaria in HIV-infection need to be emphasized despite inadequate diagnosis facilities. In such settings some patients, even when HIV-replication is controlled by ART, may continue to experience poor health due to anaemia secondary to parasites infection.

Increased CD4+Tcells susceptibility to HIV-infection caused by helminths coinfection was demonstrated by finding of a strong association between helminth co-infection and higher HIV-1 P24 antigen concentrations. This positive association can be explained by the in vivo activation of CD4+ T lymphocyte cells increased susceptibility to HIV-infection and rapidly HIV-replication in helminth co-infected HIV-patients compared to uninfected patients. HIV-1 P24 antigen level $>5 \mathrm{pg} / \mathrm{ml}$ predicts disease progression comparable to CD4+ T lymphocyte cells $<350 / \mu l$ (Schüpbach, 2003). 
We found higher HIV-1 P24 antigen concentration in parasite co-infected patients with the majority of them needing ART for survival. These findings are contrary to previous reports that show higher viral loads in helminth-free participants (Wolday et al., 2002).

A noticeable increase in CD4+ T lymphocyte cells was recorded in both parasites coinfected and uninfected patients between enrolment and at 6 months. This change cannot be exclusively associated with treatment of helminth and malaria parasites. Our patients were given Cotrimoxazole and ARVs together with treatment for parasites. A statistically significant difference in CD4+ T lymphocyte cells increase was observed between the parasites co-infected and uninfected patients. This was because a higher proportion of parasite co-infected patients had CD4+ T lymphocyte cells $<200 \mu / 1$ and started earlier ART compared to uninfected patients. Therefore, helminth or parasite co-infection treatment benefits are more increased if combined with ART and Cotrimoxazole. Cohort studies comparing very high and very low parasite intensities in HIV-1 co-infected patients can provide useful information on the minimum essential burden of parasites responsible for CD4+ T lymphocyte cells changes.

We have looked at one set of parasites and found high prevalence of malaria and helminth co-infection. Given the available various reports on parasite co-infection in HIV and AIDS patients, parasites should not be ignored in HIV and AIDS programmes. Incorporation of these programs should not wait until the conclusion of the ongoing debate to de-worm or not de-worm. Instead, parasite co-infection in HIV-infected patients' area specific prevalence data can be used confidently to guide management programs. In low parasite prevalence settings routine diagnostic screening is recommended and in settings with high parasite prevalence, mass treatment should be considered.

\section{Competing interest}

No competing interests expressed by authors.

\section{Acknowledgements}

The authors express their sincere gratitude to the patients who participated in this research. We thank all of the health workers at HIV/AIDS Management clinics and the laboratory staff of Tumbi Hospital and Chalinze Health Centre. We acknowledge the following for their valuable contributions: Rhoda Msemo (Bagamoyo District Executive Director), Dr. Koheleth Winani (Medical in-charge Tumbi Hospital), Dr. Marcel Stöckle, Susan Rumisha, Margrit Sloui, Sophia Ndwaki, Mwajuma Makala, Rose Mosses, Hassan Mkamba, Rose Mmari and Rehmant Songoro. We acknowledge the support of the Ifakara Health Institute and Swiss Tropical and Public Health Institute for their continuous support throughout all the stages of this study. The study received funding partly from International Ford Scholarships and the Swiss Tropical and Public Health Institute.

\section{References}

Assefa, S., Erko, B., Medhin, G., Assefa, Z. \& Shimelis, T. (2009) Intestinal parasitic infections in relation to HIV/AIDS status, diarrhea and CD4 T-cell count. BMC infectious Disease, 9, 155. 
Beck, D.L., Dogan, N., Maro, V., Sam, N.E., Shao, J. \& Houpt, E.R. (2008) High prevalence of Entamoeba moshkovskii in a Tanzanian HIV population. Acta Tropica 107, 48-49.

Bentwich, Z., Maartens, G., Torten, D., Lal, A.A. \& Lal, R.B. (2000) Concurrent infections and HIV pathogenesis. AIDS 14, 2071-2081.

Borkow, G. \& Bentwich, Z. (2006) HIV and helminth co-infection: is deworming necessary? Parasite Immunology 28), 605-612.

Concha, R., Harrington, W.J. \& Rogers, A.I. (2005) Intestinal strongyloidiasis: recognition, management, and determinants of outcome. Journal of Clinical Gastroenterology 39, 203-11.

Eziefula, A.C. \& Brown, M. (2008) Intestinal nematodes: disease burden, deworming and the potential importance of co-infection. Current Opinion in Infectious Diseases 21, 516.

French, N., Nakiyingi, J., Lugada, E., Watera, C., Whitworth, J.A. \& Gilks, C.F. (2001) Increasing rates of malarial fever with deteriorating immune status in HIV-1-infected Ugandan adults. AIDS 15, 899-906.

Goujard, C., Bonarek, M., Meyer, L., Bonnet, F., Chaix, M., Deveau, C., Sinet, M., Galimand, J., Delfraissy, J.F., Venet, A., Rouzioux, C. \& Morlat, P. ( 2006) CD4 cell count and HIV DNA level are independent predictors of disease progression after primary HIV type 1 infection in untreated patients. Clinical Infectious Diseases 42, 709-715.

Grant, A.D., Djomand, G., Smets, P., Kadio, A., Coulibaly, M., Kakou, A., Maurice, C., Whitaker, J.P., Sylla-Koko, F., Bonard, D., Wiktor, S.Z., Hayes, R.J., De Cock, K.M. \& Greenberg, A.E. (1997) Profound immunosuppression across the spectrum of opportunistic disease among hospitalized HIV-infected adults in Abidjan, Cote d'Ivoire. AIDS 11, 1357-1364.

Harris, R.J., Sterne, J.A., Abgrall, S., Dabis, F., Reiss, P., Saag, M., Phillips, A.N., Chêne, G., Gill, J.M., Justice, A.C., Rockstroh, J., Sabin, C.A., Mocroft, A., Bucher, H.C., Hogg, R.S., Monforte, A.D. \& May, M., Egger, M. (2008) Prognostic importance of anaemia in HIV type-1-infected patients starting antiretroviral therapy: collaborative analysis of prospective cohort studies. Antiviral Therapy 13, 959-967.

Hughes, G.J., Willey. S.J., Cochrane, A., Leen, C., Bell, J.E., Simmonds, P. (2007) Virus immunocapture provides evidence of CD8 lymphocyte-derived HIV-1 in vivo. AIDS 21, 1507-1513.

Kamya, M.R. Gasasira, A.F., Yeka, A., Bakyaita, N., Nsobya, S.L., Francis, D., Rosenthal, P.J., Dorsey, G. \& Havlir, D. (2006) Effect of HIV-1 infection on antimalarial treatment outcomes in Uganda: a population-based study. Journal of Infectious Diseases 193, 9-15.

Kaplan, J.E., Hu, D.J., Holmes, K.K., Jaffe, H.W., Masur, H., De Cock, K.M. (1996) Preventing opportunistic infections in human immunodeficiency virus-infected persons: implications for the developing world. American Journal of Tropical Medicine and Hygiene 55, 1-11.

Karp, C.L. \& Auwaerter, P.G. (2007) Coinfection with HIV and tropical infectious diseases. II. Helminthic, fungal, bacterial, and viral pathogens. Clinical Infectious Diseases 45, 1214-1220.

Karp, C.L. \& Neva, F.A. (1999) Tropical infectious diseases in human immunodeficiency virus-infected patients. Clinical Infectious Diseases 28, 947-963.

Kelly, P., Todd, J., Sianongo, S., Mwansa, J., Sinsungwe, H., Katubulushi, M., Farthing, M.J. \& Feldman, R.A. (2009) Susceptibility to intestinal infection and diarrhoea in Zambian adults in relation to HIV status and CD4 count. BMC Gastroenterology 9, 7. 
Knuchel, M.C., Jullu. B., Shah, C., Tomasik, Z., Stoeckle, M.P., Speck, R.F., Nadal, D., Mshinda, H., Böni, J., Tanner, M. \& Schüpbach, J. (2007) Adaptation of the Ultrasensitive HIV-1 p24 Antigen assay to dried blood spot testing. Journal of Acquired Immune Deficiency Syndrome 44, 247-253.

Lewthwaite, P., Gill, G.V., Anthony, H.C. \& Beeching, N.J. (2005) Gastrointestinal parasites in the immunocompromised. Current Opinion in Infectious Diseases 18, 427.

Marques, N., Cabral, S., Sa, R., Coelho, F., Oliveira, J., Saraiva da Cunha, J.G. \& Silvestre, M.A. (2007) Visceral leishmaniasis and HIV infection in the HAART era]. Acta Medica Portuguesa 20, 291-298.

Marti, H. \& Escher, E. (1990) SAF--an alternative fixation solution for parasitological stool specimens. Schweizerische Medizinische Wochenschrift 120, 1473-1476.

Martin-Blondel, G., Soumah, M., Camara, B., Chabrol, A., Porte, L., Delobel, P., Cuzin, L., Berry, A., Massip, P., Marchou, B. (2009) Impact of malaria on HIV infection. Medecine et Maladies Infectieuses. Available at: http://www.ncbi.nlm.nih.gov/pubmed/19951829 (Accessed May 13, 2010).

Masur, H., Holmes, K.K. \& Kaplan, J.E. (2000) Introduction to the 1999 USPHS/IDSA guidelines for the prevention of opportunistic infections in persons infected with human immunodeficiency virus. Clinical Infectious Diseases 30 (Suppl 1), S1-4.

Mboera, L.E.G., Senkoro, K.P., Rumisha, S.F., Mayala, B.K., Shayo, E.H., Mlozi, M.R. (2011) Plasmodium falciparum and helminth coinfections among schoolchildren in relation to agro-ecosystems in Mvomero District, Tanzania. Acta Tropica 112, 95-102. doi:10.1016/j.actatropica.2011.06.007.

Modjarrad, K. Zulu, I., Redden, D.T., Njobvu, L., Freedman, D.O. \& Vermund, S.H. (2005) Prevalence and predictors of intestinal helminth infections among human immunodeficiency virus type 1-infected adults in an urban African setting. American Journal of Tropical Medicine and Hygiene 73, 777-782.

Nielsen, N.O., Friis, H., Magnussen, P., Krarup, H., Magesa, S. \& Simonsen, P.E. (2007) Coinfection with subclinical HIV and Wuchereria bancrofti, and the role of malaria and hookworms, in adult Tanzanians: infection intensities, CD4/CD8 counts and cytokine responses. Transactions of the Royal Society of Tropical Medicine and Hygiene 101, 602612.

Paton, N.I., Sangeetha, S., Earnest, A. \& Bellamy, R. (2006) The impact of malnutrition on survival and the CD4 count response in HIV-infected patients starting antiretroviral therapy. HIV Medicine 7, 323-330.

Reeves, J.D. \& Piefer, A.J. (2005) Emerging drug targets for antiretroviral therapy. Drugs 65, 1747-1766.

Schüpbach, J. (2003) Viral RNA and p24 antigen as markers of HIV disease and antiretroviral treatment success. International Archives of Allergy and Immunology 132, 196-209.

Secor, W.E. (2006) Interactions between schistosomiasis and infection with HIV-1. Parasite Immunology 28, 597-603.

Shapira-Nahor, O., Kalinkovich, A., Weisman, Z., Greenberg, Z., Nahmias, J., Shapiro, M., Panet, A. \& Bentwich, Z. (1998) Increased susceptibility to HIV-1 infection of peripheral blood mononuclear cells from chronically immune-activated individuals. AIDS 12, 1731-3.

Tarimo, D.S., Killewo, J.Z., Minjas, J.N. \& Msamanga, G.I. (1996) Prevalence of intestinal parasites in adult patients with enteropathic AIDS in north-eastern Tanzania. East 
African Medical Journal 73, 397-399.

Whitworth, J., Morgan, D., Quigley, M., Smith, A., Mayanja, B., Eotu, H., Omoding, N., Okongo, M., Malamba, S. \& Ojwiya, A. (2000) Effect of HIV-1 and increasing immunosuppression on malaria parasitaemia and clinical episodes in adults in rural Uganda: a cohort study. Lancet 356(9235), 1051-1056.

Wolday, D., Mayaan, S., Mariam, Z.G., Berhe, N., Seboxa, T., Britton, S., Galai, N., Landay, A. \& Bentwich, Z. ( 2002) Treatment of intestinal worms is associated with decreased HIV plasma viral load. Journal of Acquired Immune Deficiency Syndromes 31, 56-62. 